\title{
Surveillance and exclusion practices in the govemance of access to shopping centres on periphery estates in the UK*
}

\author{
J ohn Fint1
}

\begin{abstract}
The UK government has renewed its focus upon retail crime in deprived neighbourhoods. This paper discusses the roles of cities as sites of consumption and places the growth of surveillance and techniques of exclusion in shopping centres within wider trends towards the privatisation of public space. The paper seeks to explore the spatial, social and political relations revealed through studies of the surveillance and exclusionary mechanisms, including banning orders, deployed in shopping centres located on periphery estates in two Scottish cities. It identifies the tensions and synergies arising from the dualities of these centres as sites of consumption and civic engagement, examines the specific dynamics arising from the particular community contexts of the centres and explores how practices of surveillance impact on various dimensions of social exclusion.
\end{abstract}

\section{Introduction}

Within crime reduction partnerships in the UK there is a growing focus upon retail crime in deprived communities. In 2001 the Home Office launched a $£ 15 \mathrm{~m}$ initiative to reduce crime in shopping centres in the most deprived areas of England and Wales. The then Home Secretary stated: "Communities deserve decent shopping facilities...local shops are at the heart of communities" (Downing Street news release, 2001). Access to crime-free shopping centres is conceptualised as a vital mechanism for achieving neighbourhood renewal and building sustainable communities in the most deprived residential areas of the UK (Social Exclusion Unit, 2001; Office of the Deputy Prime Minister, 2003). The use of surveillance techniques in retail units located in deprived communities has a specific importance for concepts of consumption, citizenship and exclusion. Residents in deprived periphery housing estates are already 'disadvantaged consumers' who often live in what have been termed 'food deserts', lacking local

\footnotetext{
* I wish to acknowledge the role of my colleague Annette Hastings in undertaking this research, which was funded by the Nuffield Foundation. I also wish to thank all the research participants and the Surveillance \& Society journal editor and referees.

${ }^{1}$ Centre for Regional Economic and Social Research, Sheffield Hallam University, mailto.j.f.flint@shu.ac.uk
} 
access to affordable, good quality retail and grocery goods (Wrigley, 2002; Whelan et al., 2002). Further exclusion from opportunities for consumption and civic engagement provided by local shopping centres therefore has potentially more fundamental consequences for banned individuals. These shopping centres are located in the heart of residential areas, with security personnel often living in nearby houses and many shopping centre users well known to management and staff, resulting in processes of surveillance and exclusion being embedded within local community dynamics to a greater extent than in town and city centres.

The Home Office has introduced Safer Shopping Awards which aim to reassure customers and staff about security standards in shopping areas and reduce fear of crime (Home Office, 2000). Two of the inaugural winners of these awards introduced exclusion notices within their crime reduction strategies. These exclusion notices are used in conjunction with CCTV and the pooling of police photographs of known offenders to ban individuals from certain retail premises (Home Office, 2000; Metropolitan Police, 2000). The growing practice of utilising exclusion notices in shopping centres, in particular pertaining to young people, has been noted in the UK (Jeffs, 1997), North America (Hopkins, 1994) and Australia (White, 2001; Grant, 2000). The use of exclusion orders in shopping centres located in deprived neighbourhoods is the focus of this paper, and occurs in the context of a greater control of public spaces, enacted through new mechanisms including Anti-social Behaviour Orders, Dispersal Orders and Curfew Orders, which have predominately been deployed against young people in deprived neighbourhoods (Flint and Nixon, 2006).

The paper begins by discussing the role of consumption in the urban experience and examines how techniques of surveillance and exclusion have been conceptualised as contributing towards an enhanced social control and privatisation of public spaces, with new mechanisms of surveillance, speculation and recognition enacted by shopping centre management and security personnel. These processes raise important questions about the efficacy and accountability of surveillance and exclusion techniques, located within wider conflicts about the legitimate use of public space by different sections of communities and the role of consumption as a manifestation of citizenship. The paper then examines the use of surveillance and exclusion notices within social control techniques utilised by managers and security personnel of shopping centres located on periphery housing estates in two Scottish cities. The strategies of prioritisation, recognition and speculation that comprise surveillance and the construction of order within the centres are identified and related to the commercial and civic functions of these centres. The paper concludes that surveillance mechanisms on periphery housing estates have particular features and outcomes which require to be recognised within debates about social exclusion, consumption and citizenship.

\section{Consumption, Citizenship and Community}

Cities are conceptualised as sites of constant processes of exclusion and inclusion arising from the utilisation of social and economic power and conflicts about rights and responsibilities (Christopherson, 1994). The urban landscape both reveals the spatial consequences of these conflicts and itself produces and forms new types of interactions (Zukin, 1991; Bickford, 2000). 
For commentators such as Christopherson (1994) and Davis (1990) the primary features of the contemporary city landscape are control, manipulation and separation manifested by fortresstype developments and the intensive management of urban space. Within these processes, consumption becomes the defining element of urban citizenship (Christopherson, 1994; Shields, 1992; Bauman, 1998) and the material forms and experience of shopping and access to shopping centres therefore contribute to definitions of urban citizenship and social exclusion (Christopherson, 1994; Shields, 1992). Despite this, excluded consumers have been a neglected aspect of social exclusion debates in the UK (Williams and Windebank, 2002).

Consumption represents a form of social exchange, as Shields (1992: 4-5) describes: "The mall forms the centre of an urban constellation and a social community is born which appropriates the mall as a surrogate town square". For Shields, shopping represents a communal as well as functional activity, which "both solidifies the sense of the personal sense and confirms it as social through common membership in a shopping fraternity" (ibid). Shopping centres act as potential sites of civic identification, engagement and interaction and become "de facto community centres" (ibid). This may be a particularly important function in deprived periphery housing estates which lack alternative arenas of public space and civic engagement.

\section{Private Spaces of Control and Exclusion?}

This conceptualisation of shopping centres as new town squares is problematic. Shopping centres have been characterised as socially divisive, excluding those who lack the necessary cultural or economic capital who are then marked out as undesirable due to their appearance or behaviour (Miller et al., 1998), illustrated recently by the banning of teenagers wearing hooded tops from the Bluewater shopping complex in Kent. It is claimed that these boundaries between consuming and non-consuming individuals are strengthened by the emergence of fortified consumer 'enclaves' which appropriate previously public spaces, creating cities of no-go zones for 'flawed consumers' defined as 'objects out of place' (McCahill, 1998: Davis, 1990; Bauman, 1998; White, 2001) within cities re-conceptualised as private sites of consumption rather than civil arenas of citizenship (Davis, 1990; Christopherson, 1994).

Shopping centres epitomise the construction of sanitised consumption environments predicated on eliminating the unpredictability and dangerousness of urban interactions:

The popular appeal of shopping centres...derives in no small part from their ability to manage diversity using the power of privatised space (including surveillance and other informal means of social control) to exclude those who are considered undesirable. By managing the mix of retail outlets and controlling accessibility to the centres (if necessary by forcible ejections and exclusions) the managers of these places are able to reduce the risks of unanticipated encounters with people shoppers find threatening, while actively promoting the virtues of familiarity

(Miller et al., 1998: 105). 
Whilst shopping centres may appear spaces of democracy and access for all, they are intensively managed spaces (Smithsimon, 1999; Shields, 1992). Shopping centres are privately owned sites that act as public spaces, within which shoppers must temporarily surrender certain civil liberties (Miller et al., 1998) and a range of technologies are deployed to prevent non-consuming behaviour, including narrow walkways, loud muzak and limited seating (Shields, 1989; Smithsimon, 1999; Reeve, 1998). The 'selectively permeable' quality of shopping centres (Smithsimon, 1999) is maintained by local ordering strategies (Coleman and Sim, 2000) which manage out forms of conduct and access to the centres based on assumptions of appropriate (consuming) behaviour (Reeve, 1998; McCahill, 1998) and which prohibit or marginalise 'illegitimate' users, often young, male and black individuals (Grant, 2000; Evans, 1995; Miller et al., 1998; Bickford, 2000; Philips and Cochrane, 1998; Roderick, 1998). Although appropriate behaviour is usually defined by shopping centre managers as acts of consumption, studies indicate that up to a third of shoppers make no purchase, and for young people in particular shopping centres are arenas for socialising rather than purchasing goods (Shields, 1989; Dangar, 2000), creating sites for conflict based on definitions of acceptable behaviour. The surveillance of shopping centre users and the distinction between shoppers and non-shoppers, and the subsequent exclusion of individuals are enacted by security guards whose decisions are based on internalised management norms of conduct and rules and whose speculation about individuals' motivations and conduct are influenced by their own prejudices and judgement (Shields, 1992; Graham, 1998). This paper now turns to exploring these practices of surveillance, control and exclusion in the context of governing access to shopping centres located on periphery housing estates.

\section{The Research}

The research was conducted between August and December 2002 in two shopping centres located in periphery housing estates in Edinburgh and Glasgow. The methodology included analysis of management company documentation and media reports; site visits to the centres, including CCTV control rooms; interviews with centre managers (3), interviews with security personnel (4); interviews with police officers (2); social workers (2); regeneration practitioners (2); community newspaper editors (2); individuals subject to exclusion orders (2); two focus groups with teenage users of the centres ( 8 individuals in each group) and random (and therefore not representative) survey interviews with 30 shoppers in each centre.

\section{The Case Study Shopping Centres}

Both shopping complexes are centrally situated within large housing estates located on the periphery of their respective cities, built to house populations displaced by central city slum clearance programmes. The Glasgow estate, built in the 1950s, is located on the eastern fringe of the city, approximately five miles from the city centre, and has a current population of 30,000. The Edinburgh estate was constructed in the late 1960s on the south-western edge of the city, four miles from the city centre and has a population of 11,000. Both estates suffer multiple deprivation including high levels of unemployment, crime and poor health in addition to having large concentrations of young and elderly residents. Each estate has been subject to extensive long-term regeneration activity, which at the time of the research was co-ordinated by local 
Social Inclusion Partnerships.

Both shopping centres were built in the 1960s and both underwent major refurbishment in the mid 1990s, including the renaming of the Edinburgh centre in 1997 as part of an estate-wide rebranding marketing exercise. At the time of the research each centre attracted sixty to seventy thousand users each week. Both centres are located in the 'town centres' of their estates, adjacent to libraries, social work and housing departments, public houses and transport hubs. The Glasgow centre is built on two levels with the majority of the forty retail units located on a lower floor thoroughfare, based on a high street design with major entrances at each end and further entrances from a lower level car park and two entrances on the upper tier. The Edinburgh centre is built to a town square design on two storeys and contains 31 retail units with a major entrance from the estate's civic square and three main upper-level entrances accessed from the car park. The retail tenant mix is similar in both centres, comprising economy goods stores, major food and pharmacy chain outlets, clothes shops, community or educational units and several cafes and fast food facilities.

\section{Crime and Disorderin the Shopping Centres}

In the mid 1990s both shopping centres suffered from high retail tenant turnover, falling user numbers and poor local reputations, exacerbated by rising levels of crime and disorder, including significant drug dealing activity. A local paper referred to the Edinburgh centre in 1994 as 'a violence torn shopping mall' experiencing 'open warfare.' There were also concerns amongst local people about the inadequacy of security, including the conduct of security guards. During this research the majority of retailers and shoppers in both centres reported that present levels of crime, particularly shoplifting, verbal and physical assaults and racial harassment were considerably lower than in the mid 1990s. Whilst previously the reputation of the shopping centres kept shoppers away, retailers no longer felt this to be the case and many contrasted the security of the centre favourably with other small retail units on the estates.

The extent and forms of disorder were similar in both centres, with estimates from retailers and security personnel of between 10-20 incidents per month, mostly shoplifting; with some incidences of domestic arguments, disturbances involving groups of young people and individuals under the influence of alcohol or drugs. Physical and verbal assaults or fights were reported to be very rare, with several months passing between major disorder incidents. The perceptions of the shoppers surveyed in this research, including young people in focus groups, supported this, with the majority feeling safe or very safe in the premises and reporting little or no disorder, other than shoplifting, although a minority of surveyed shoppers in both centres felt that occasional acts of verbal intimidation still occurred. However, a third of shoppers in both centres reported concerns about disorder occurring around entrances and immediate surroundings, including drug dealing, vandalism and large groups congregating.

\section{The Aims and Rationales of Surveillance Practices}

The deployment of surveillance and security policies and practices in both centres were based on a dual conceptualisation of the centres as sites of consumption and arenas for providing 
community services and social interaction. Both centre managers initially identified the primacy of consumption within their regulation of behaviour:

'I've two rules here. Don't do anything to stop people buying and don't do anything to stop people selling"

(Centre Manager, Glasgow).

"The aim of the centre is to enable people to spend money"

(Centre Manager, Edinburgh).

This focus on consumption and the private ownership of the centres was symbolised in the signage of the Edinburgh centre, including prominent 'No Loitering' notices and messages at the centre entrances reading 'This is a private place. The management reserve the right to refuse admission to any member of the public.' Prominent notices in both centres also informed users they were subject to CCTV coverage and gave the name and contact details of the private companies operating the cameras.

However, both centre managers also recognised that the centres were the only locally accessible providers of essential local services including post offices, chemists, banks and public telephones. An important contextual factor in the implementation of surveillance and security measures was the explicit recognition by both centre managers that their users were overwhelmingly from the surrounding estates and that their centres provided retail provision for local residents who were often unable to access alternative sites due to the isolated location of the estates, poor transport connections to city centres and other retail complexes and the prohibitively high cost of transport for individuals on low incomes. This vital 'lifeline' function of the centres was borne out by centre users:

'I've got kids, I can't go anywhere else"

(Female shopper, aged 28, Edinburgh).

'I couldn't go anywhere else, because I can't walk far and the transport is complicated to other centres"

(Female shopper, 67, Edinburgh).

The added severity of banning individuals who were already excluded from accessing alternative shopping facilities was an important aspect in decisions to ban individuals and subsequent review and readmission processes. Furthermore, both centres provided units for local community organisations and regeneration agencies, educational projects, learning centres and citizens' advice centres. Managers identified these units as amongst the most important facilities attracting users to the centres. In addition, the conceptualisation of the centres as important meeting places within the estate influenced the management's response to the behaviour of particular groups:

'The shopping centre is the estate's town centre. I would call us a community centre...There's a hard core of old biddies who spend their days here, who sit on the bench and chin wag. That's fine, we're happy with that" 
(Centre Manager, Edinburgh).

The communal interaction function of both centres is evidenced by the fact that nearly all of the adult shoppers surveyed reported spending a considerable length of time in the centres at each visit, often up to two hours, and making use of the cafes and public seating areas and regularly using the centres as locations for meeting up with families and friends.

\section{Local Ordening Strategies}

However, the pressure to maintain the economic and commercial viability of the centres is the predominant contextual factor in management strategies. At the time of the research the Edinburgh centre had only two thirds of its retail capacity occupied, although the Glasgow centre had only two empty units. Both centres had sought to diversify their retail tenant base beyond the budget goods stores: "We try to get away from the estate's reputation, make the place more upmarket" (Operations Manager, Glasgow). These processes prioritise the needs of particular groups and subsequently influence how surveillance and control techniques are deployed against individuals. For the Edinburgh centre manager, security mechanisms served the primary aim of "protecting the asset and the rights of the three hundred people who work here." Similarly, he linked security to improving the external image of the centre and attracting non-local shoppers: "We place great importance on visitors from outside the estate. If they witness trouble they will never come back." The Operations Manager of the Glasgow shopping centre also identified particular shoppers who needed to be attracted: "We need [rigorous security strategies] in order to create a safe environment, where women and kids are protected."

These management priorities are manifested and filtered through controlling access to the centres and regulating conduct within them. Both centres deployed a range of surveillance and security techniques to achieve this. These included shuttered and reinforced doors and alarm systems. Both centres also operated a bank of approximately 20 internal and external CCTV cameras which were constantly monitored by security staff in on-site multi-screen control rooms. The most visible form of surveillance and control in the centres was provided by uniformed security guards. Both centre management firms had total staff teams of approximately 15 security personnel, with a supervisor and two or three guards patrolling the public areas of the centre at any one time and one or two officers monitoring CCTV cameras. In addition the larger food stores and pharmacies in both centres employed their own security personnel. There was a regular exchange of information between these store guards and the centre management security teams, but the internal management of surveillance and security remained the responsibility of individual retailers.

The security guards were the arbitrators of access to, and accepted conduct within, the centres. The function of these guards was broadening from a surveillance and control to a more multidimensional role, which centre managers and guards themselves identified as comprising three elements: a 'traditional' security role of managing crime and disorder (surveillance, controlling access, moving individuals on, reacting to incidents); a health and safety role (administering first aid, fire fighting, equipment maintenance) and an increasingly prevalent public relations and 
customer liaison function (welcoming shoppers, providing directions, carrying shopping, ordering taxis).

Security personnel in both centres had received short induction training, were subject to an ongoing staff development programme and were required to complete a probationary period of employment. Analysis of these training programmes indicated a shift from a focus on guarding, dealing with 'undesirables' and physical interventions towards an emphasis upon customer liaison and relations: "We are moving away from any thug element, of the use of physical force, to a new approach based on interaction, focusing on skills of dealing with people, coaxing them along" (Centre Manager, Edinburgh). Security guards had undertaken certificated courses in drugs awareness and working with particular groups such as teenagers and people with physical disabilities or learning difficulties. Indications of the success of such training processes may be evidenced by the majority of surveyed shoppers in both centres reporting security guards to be welcoming and effective in deterring or responding appropriately to disorder. However, such perceptions were not universal amongst all groups of centre users.

\section{Processes of Exclusion: Surveillance, Speculation and Rec ognition}

Decisions about who is subject to surveillance and when intervention is appropriate required security personnel to differentiate between legitimate and illegitimate activities within the centres. Whilst there were no formal written policies or procedures about when intervention was required, the security guards themselves were confident about the efficacy and accuracy of their own strategies of speculation and recognition: "You can tell the good from the bad" (Security Guard, Glasgow). Within the rules that guards constructed, it was apparent that non-purchasing activities were tolerated to an extent: "People are here at half eight every day, they sit for hours, the same people every day" (Security Guard, Glasgow). This involved distinguishing 'genuine' activities from 'loitering' which was not tolerated: 'You get groups of people hanging about, we'll have a word in their ear, ask them if they are in to buy something, they are not allowed to loiter" (Security Guard, Glasgow). Thus making a purchase was utilised as the basis for distinguishing between behaviours, but it was apparent that surveillance strategies and subsequent interventions were based on conflicting interpretations that the guards gave to similar behaviour amongst different groups: "Old biddies, they're fine, they sit on the streets, we see the same faces every day. For some older people, this is all they've got, or women with kids. We move on young people if they are noisy or are giving folk looks" (Security Guard, Glasgow). This blurring of acceptable and unacceptable behaviour is therefore based on subjective interpretations, for example about what constitutes 'giving folks looks.' Similarly, a distinction is drawn between elderly users and "alcoholics hanging about and the gossip queens: we move them on if they are attracting attention" (Security Guard, Edinburgh). Again, how a 'gossip queen' is identified is a matter of guard's individual speculation and interpretation of behaviour.

Surveillance and control practices were differentially applied against young people, particularly when they were unaccompanied by an adult, with young people in both centres reporting being asked to leave despite being on their own or not engaging in disorderly conduct: 'T've been put out for hanging about when I've been by myself...it's just dealing with stereotypes. If you are 
young you must be trouble" (Male user, 15, Glasgow). This differentiation on the basis of age and appearance was also identified by a police officer in Glasgow: "The guards don't like young gregarious laddies who are mouthy and wear baseball hats, they are seen as aggressive and they will be dispersed, but they'll let grannies or mothers sit for hours. They are selective."

These dynamics of surveillance and exclusion and the interface between security personnel and users replicate similar processes in town centre shopping areas. However, the location and community context of the case study shopping centres in periphery estates had a number of specific elements. Firstly, many of the security guards lived on the estates. Whilst the centres' security teams stressed the benefits of this in regard to improved intelligence, it created pressures on security guards arising from contact with banned individuals in local contexts away from the centres. For example two security guards in Edinburgh reported being approached in a local pub by an individual demanding to be readmitted. Conversely, the knowledge that guards accumulated from their membership of the local community, particularly with regard to individuals' reputations, resulted in guards' associating individuals' alleged behaviour in their local communities with potential disorder in the centres and prohibiting entry to these individuals on a pre-emptive basis. 'They [the guards] don't like anything to do with drug activities; they don't like your face so they bar you. But the thing is you have a drug problem, it doesn't mean you are into shoplifting" (Former Glasgow centre user, male, 35). Here an alleged drug habit became conflated with future misconduct in the centre, and was used as a basis for denying this individual access. The particular dynamics of youth cultures on the estate also influenced strategies of surveillance and access control, based on speculation about likely behaviour: "We've had gang members in the centre. They are followed and escorted off the premises. You do get young people in who are from either end of the scheme, that can lead to fights" (Security Guard, Glasgow).

\section{Exclusion Orders}

Both centres have operated a system of exclusion orders since the mid 1990s. These were regarded by management teams as an important and effective weapon in their security armoury, although security personnel in both centres claimed they were only utilised as a last resort, "Exclusion is counter to the face we are trying to portray, we don't want overt messages...it's not my policy to ban people. After all, I want them to come in and spend money" (Centre Manager, Edinburgh).

The Edinburgh centre operated a formal two-tier system of exclusion categories. Individuals on the 'A List' had committed a criminal offence in the centre and were barred from all areas of the centre, for a standard duration of six months. Individuals on the 'B List' were admitted to the centre, but were subject to surveillance and assessment. They were escorted around the centres by security guards and they remained banned from particular retailers. The 'B List' was used for offences not deemed to warrant total exclusion and also as a six month probationary mechanism for individuals previously on the 'A List'. The Glasgow centre operated a less formal system, without such classifications. 
In both centres offences resulting in permanent or longer-term exclusion included shoplifting, drug dealing, physical and verbal assault and other offences that resulted in police involvement. Acts of disorder including shouting and swearing, drunkenness and domestic disputes were likely to result in short bans. These exclusion orders affected a significant number of individuals in both centres, with managers and guards in the Edinburgh centre indicating around two hundred names on the 'A List' and a further sixty on the 'B List', whilst security personnel in the Glasgow centre estimated that between one to two hundred individuals were subject to some form of exclusion. In both centres young males were most likely to be subject to an exclusion notice.

Management teams in both centres indicated that they had established clear operational procedures and transparent lines of authority and accountability for issuing exclusion notices in order to demonstrate that 'due process' had been followed. In both centres, a security guard, based on his or her own observations, was autonomously able to ban an individual for the remainder of that day. Longer-term exclusions required authorisation from a senior manager. The procedures in both centres indicated that individuals were to be informed in writing of the offence they had committed and the duration of their exclusion order, although this procedure was not always followed. There were also ambiguities surrounding the commencement of an exclusion notice and its link to formal criminal proceedings. Whilst centre managers stated that long term exclusions were only enacted subsequent to individuals being charged with an offence by the police, some individuals subject to long term exclusion orders argued that they had never been formally charged by the police, nor presented with the evidence of their offence by the centre management.

Management teams in both Edinburgh and Glasgow stressed the importance of being seen to be fair, only using exclusion as a last resort and of operating a policy which sought to facilitate the re-admission of banned individuals where possible. However, managers and guards in both centres were explicit in stating that certain individuals would not be readmitted under any circumstances, for example those who had assaulted guards or had been banned for a second time. Managers indicated that they responded to individual circumstances and treated each exclusion on a case-by-case basis. Bans were enacted flexibly, both in terms of their duration and their spatial dimensions, with some individuals being allowed access to the centre but excluded from certain shops.

The particular locational context of the shopping centres influenced the enactment of the exclusion notices. Security teams in both centres reported an awareness of the serious impacts upon excluded individuals given the lack of alternative local retail facilities. Whilst security managers argued that this enhanced the deterrence element of the notices, they had also established processes to mitigate some impacts of the bans. In Edinburgh, individuals subject to a complete ban were allowed an escorted visit to the centre in order to make alternative arrangements at the Post Office and chemist and several individuals subject to banning notices were allowed continuing escorted visits to collect benefit payments and medical prescriptions. In the Glasgow centre banned individuals were still allowed access to the job centre located within the premises. These procedures lessened some of the exclusionary impacts of the notices. There was also evidence of co-operation between social workers and centre management teams in both Edinburgh and Glasgow, involving social workers escorting banned individuals on pre- 
arranged visits to the centres and social worker involvement in drawing up 'future behaviour contracts' to facilitate the readmission of excluded individuals.

\section{Readmission and review procedures}

In both centres the lists of banned individuals were subject to review, with a formal six-monthly review procedure in Edinburgh and an informal continual reassessment process in Glasgow. In both centres readmission required a proactive gesture by banned individuals to instigate the readmission process, through making a written request and giving guarantees about future conduct. This condition applied even when the period for a time limited exclusion notice had expired, and, combined with the lack of publicity and formal processes, caused some concern amongst local social workers:

"There is a need for advocacy here, it seems there is no way individuals are getting back in by themselves. A lot of people couldn't write a letter, or would lack confidence...Do clients even know about the review process? Maybe they think that is it, I'm out forever."

(Social Worker, Edinburgh).

A police officer in Glasgow also reported that he had contacted social workers on behalf of individuals who were uncertain about readmission procedures. The centre manager in Edinburgh identified that requests for readmission were themselves used as a means for assessing future conduct:

"Sometimes these letters [requesting readmission] are on the back of fag packets: they go in the bin. If it looks like they've thought about it and made some effort then it [readmission] is not a problem. I've had them phoning up saying they can't write but I ask them to find someone who can write a letter for them: it's their responsibility because it was their behaviour in the first place."

Despite this rhetoric, managers in both centres emphasised the flexibility of their schemes which enabled readmission and consideration of mitigating circumstances, commonly involving offences committed by individuals when they were younger or under the influence of drugs, "We give people a chance. There was one girl. She used to cause all kinds of bother so we barred her. Then she came off heroin and she was a different person, I had no problem in letting her back in." (Operations Manager, Glasgow)

There were no formal criteria or published procedures for readmission to either centre. Representations were occasionally made by banned individuals' families or friends to which managers often seemed responsive. Managers in both centres had also received solicitor's letters, either challenging the legal grounds of the exclusion or explaining mitigating circumstances, backed up by reports from social workers or alcohol counsellors, although no formal legal challenge had been pursued by a banned individual. The private governance of the centres is illustrated by final decisions about readmission being entirely at the discretion of the centre managers, often taken in consultation with other security personnel, but without reference to police officers or social workers. Centre managers had only limited control over access to 
individual retail units, many of which independently enforced and policed their own exclusions of individuals and enacted their own surveillance and readmission criteria.

\section{Enforc ing Exclusion Notices}

Both centres had a series of surveillance and intervention mechanisms for enforcing exclusion notices, although it was reported that the majority of banned individuals made no attempt to access the centres during their ban periods. When banned individuals were identified either by guards on patrol at the entrances or by CCTV operators in the control room, security personnel would attempt to prevent that individual from entering the premises. If an individual did gain access they were followed by security personnel and retailers were requested not to serve them. The police were also contacted on rare occasions when a banned individual refused to leave. The distinctions between the powers and responsibilities of the police and centre security teams were unclear in such situations. Whilst local police officers were adamant that they could not enforce exclusion notices in the centres, they were equally clear that security guards could not physically remove individuals. It was also the understanding of security personnel that the centre management could refuse access to a banned individual, but could not then subsequently proceed with trespass charges. Police officers in both Edinburgh and Glasgow reported that they had never witnessed a scenario in which a banned individual had refused to leave a centre once the police were present.

The surveillance, identification and challenging of individuals subject to exclusion orders was dependent on the ability of security teams to recognise those individuals. The security guards interviewed in the research claimed that they could identify all banned persons, based on both computer records and through the importance of local knowledge arising from the predominance of regular repeat shoppers drawn from the surrounding community. In Edinburgh, these recognition processes were facilitated by a photograph machine, linked to the CCTV system that deployed facial recognition software to store and match images of banned individuals along with their name, a description of the incident leading to their exclusion order and an incident number. Despite this confidence in the ability to utilise surveillance mechanisms to identify and challenge individuals, one security guard in Glasgow indicated that he and his colleagues would "always err on the side of caution" and would only challenge persons they were completely certain were subject to an exclusion notice. However the efficacy of these recognition strategies and this cautious approach were challenged by a number of adult and teenage centre users who reported that they had been asked to leave the centre by security personnel mistakenly believing they were subject to exclusion notices.

\section{Disc ussion: The Parameters of Exclusion}

This study of surveillance and exclusion techniques deployed in shopping centres on periphery housing estates raises a number of questions about the efficacy of such practices, the legitimacy and accountability of private forms of governance and definitions of social exclusion. The centre managers, security guards, police officers and individual retailers were unanimous in their support for the use of exclusion policies. This was related firstly to an improvement in the conduct of banned individuals, who were reported to have 'learnt their lesson', with the majority of 
readmitted persons causing no further disturbances, and therefore being able to access the consumption opportunities that were provided by the centres.

Secondly, and more fundamentally, the formal exclusion enacted by banning notices was conceptualised as being targeted on individuals whose actions led to the informal exclusion of others. There was overwhelming support for the banning policies amongst centre users themselves, based on a recognition that disorder in the centre had led to vulnerable groups being excluded from access. "The centre used to be a no-go zone for grannies" (Police Officer, Edinburgh).

'They don't tolerate gangs of lads in the centre now and that means it is less intimidating for your run of the mill shopper...I used to take someone with me when I went to the centre, but now I go myself. The centre has a better balance of people in it, more women and older folk, or families with kids."

(Female shopper, 29, Edinburgh).

Thus local ordering strategies based on the surveillance and exclusion of particular individuals or groups is directly linked to facilitating the access of others. The evaluation of the efficacy and social justice of exclusion orders requires a recognition that governance of access to the centres will always involve a politics of balancing and prioritising the interests of different user groups. The importance of how this local politics of exclusion plays out is magnified by the centrality of these centres to the consumption opportunities and social and civic processes of their surrounding communities:

"When they put the shopping centre up there was no place for the community here, but the centre became the community place. It became suitable because they had not had shopping facilities on the estate, there was nothing else, although there was some community spirit, and it's a close knit community. This is a community gathering place."

(Male shopper, 59, Edinburgh).

Whilst the debates around food deserts, disadvantaged consumers and poor retail facilities as an element of social exclusion in deprived neighbourhoods have focused on shopping centres as sites of consumption, they are equally arenas for social interaction and civic engagement which are also constituent dimensions of urban citizenship. This requires conceptualisations of social exclusion to be broadened to the community development aspects of shopping centres, and specifically shopping centres located in the heart of deprived communities on periphery estates, where their presence, functions and the manifestations of processes of inclusion and exclusion are magnified and made explicit as they are visibly played out in local arenas and more directly reflect conflicts over the ownership and legitimate use of space occurring in local communities than is the case in the more anonymous context of city centre retail complexes.

In this broader understanding, the study shopping centres sometimes acted as sites for mitigating community conflicts, for example arising from tensions between ethnic groups:

"Lots of Muslim women meet here, ethnic minorities use it as a meeting place, not the males but 
the women and children, it's important to them" (Male shopper, 59, Edinburgh). These periphery estate shopping centres are directly affected by, and aware of, community tensions and at times have responded accordingly, for example the Edinburgh centre management asked local refugees living on the estate to open a new market facility in the centre as a symbolic attempt to reduce local community tensions. A number of teenagers in both Edinburgh and Glasgow also reported that the centres acted as safe havens, providing an opportunity to socialise with young people from other areas of the estates, which was problematic in the surrounding streets given the prevalent territorialism and gang cultures.

The community development and 'town square' functions of the centres (see Shields, 1992) were also manifested by the free provision of empty retail units for community events, health promotion and educational displays, charity events run by centre staff and both centres organising free summer and Christmas activities for local children, although not all shoppers surveyed during the research were aware of these activities.

There are also synergies between the commercial function and viability of the centres and the wider social inclusion of local residents. The focus of the centre management teams on attracting retailers, maximising shopper numbers, improving the reputation of the centres and prioritising shoppers from outwith the surrounding areas was perceived to necessitate the surveillance and exclusion of some individuals. However, this was balanced by a recognition that the closure of the centres would greatly increase the social exclusion of local residents, who were already on low incomes and had little access to alternative facilities. This study has confirmed the importance of consumption to urban citizenship, and maintaining economically sustainable, accessible and affordable retail opportunities for local residents was conceptualised as a vital mechanism for mitigating other dimensions of the social exclusion experienced on the estates. Whilst the prioritisation of economic competitiveness and commercialism may result in divisive, discriminatory and draconian surveillance and exclusion practices targeted at vulnerable groups, particularly in city centres (Coleman and Slim, 2000), the creation of successful retail premises is also an important part of neighbourhood renewal strategies aimed at reducing the exclusion of deprived communities from consumption opportunities, improving the image of estates and attracting new populations (Wrigley et al., 2002), and this partly explains why the use of exclusion notices was supported by all the regeneration agency officers interviewed in this research.

Given that consumption, access to public spaces and civic interaction are key dimensions of urban citizenship and the particular importance of shopping centres on periphery estates as arenas for facilitating social inclusion, through retail provision and social interaction but also as sites for accessing other avenues to inclusion including benefit advice, health facilities, job centres, education and training units; how processes of surveillance and exclusion are governed in these centres is of paramount importance. Some of the concerns about punitive and draconian mechanisms of exclusion in the private governance of shopping centres were not fully borne out by this research. In part this arises from the recognition by the centre management teams that overtly coercive forms of surveillance and control were damaging to the images and commercial interests of the centres. Whilst this study revealed the 'selective permeability' (Smithsimon, 1999) of the centres, the increased training of security guards, internally accountable and transparent 
structures of responsibility, written processes for intervention and liberal interpretations of exclusion policies provided a fairly robust framework of safeguards and mitigated some of the additional exclusionary effects arising from the centres' locations on isolated periphery estates populated by deprived communities. Local police officers believed that security personnel in both centres acted appropriately and did not breach the limits of their powers, and the police had not received complaints from the public about the centre management or security guards. One consequence of this perceived effectiveness was that the police in both Edinburgh and Glasgow had reduced their own patrols in the centres. However, this did not equate to allowing the centres to police themselves. Whilst police officers co-operated with centre security teams and pooled intelligence where appropriate, they also emphasised their role in monitoring the conduct of the guards and regularly inspecting CCTV control rooms and footage to ensure that protocols were being followed.

However, the private governance processes in the centre relating to surveillance and exclusion were not subject to the same degrees of regulation as those of public enforcement agencies. In particular, the informal and at times arbitrary mechanisms for excluding and subsequently readmitting individuals, confusion over the legality of exclusions, inconsistent linking of exclusion notices to legally proven offences, the lack of advocacy and support to facilitate the readmission of some vulnerable excluded individuals and practices of proactively excluding young people not committing an offence suggest the need for more formalised systems of accountability to be introduced, and greater partnership working between the centre management teams, local social work departments and youth agencies. This is of further importance given the blurring between private and public forms of surveillance and control and an extension of private spheres of governance. For example, the centre management teams worked closely with local schools in developing co-ordinated truancy strategies in which unaccompanied children in the centre during school hours were reported to the police and head teachers and the schools operating policies banning children from the centres during break and lunch times.

In conclusion, the use of surveillance and exclusion practices to govern the access to shopping centres on periphery housing estates may be seen as part of a wider strengthening of the policing of public and semi-public spaces in deprived communities through new mechanisms including Anti-social Behaviour Orders, Dispersal Orders and Curfew Orders (Flint and Nixon, 2006). These processes raise fundamental questions about how urban citizenship and social exclusion are defined and the importance of consumption and civic engagement to daily urban life. The governance of access to shopping centres on periphery estates has both inclusionary and exclusionary effects for deprived populations, necessitating a broader conceptualisation of the role of retail facilities in neighbourhood renewal.

\section{References}

Bauman, Z. (1998) Work, Consumerism and the New Poor. Buckingham: Open University Press.

Bickford, S. (2000) Connecting Inequality: City Spaces and the Architecture of Citizenship. Political Theory, 28(3): 355-376. 
Christopherson, S. (1994) The Fortress City: Privatized Spaces, Consumer Citizenship. In A. Amin (ed.) PostFordism: A Reader. Oxford; Blackwell, 409-427.

Coleman, R. and Sim, J. (2000) You'll never walk alone: CCTV surveillance, order and neo-liberal rule in Liverpool city centre. British Journal of Sociology, 51(4): 623-639.

Dangar, L. (1998) Shopping Centres: The Changing Face of the Community. Australia: Dangar Research Group/Property Council of Australia.

Davis, M. (1990) City of Quartz: Excavating the Future in Los Angeles. New York: Vintage.

Downing Street Newsroom (2001) £15 million to drive crime out of shopping centres. News Release, 27/06/2001. London: Downing Street Newsroom.

Evans, K. (1995) Black British: Segregation, surveillance and the reconstructed late modern city. The British Sociological Association Annual Conference, Leicester, England 10 -13 April.

Flint, J. and Nixon, J. (2006) Governing Neighbours: Anti-social Behaviour Orders and New Forms of Regulating Conduct in the UK. Urban Studies, 43(5/6).

Graham, S. (1998) Towards the fifth utility. On the extension and normalisation of public CCTV. In C. Norris, J. Moran and G. Armstrong (eds.) Surveillance, Closed Circuit Television and Social Control . Aldershot: Ashgate, 89-112.

Grant, C. (2000) 'Banning the Banning Notice: Banning notices, shopping centres and young people. Alternative Law Journal, 25(1): 32-44.

Home Office (2000) First Awards for Safer Shopping-News Release, 25/05/2000. London: Home Office.

Hopkins, J. (1994) A consumption of resistance: challenging the socio-legal identities of malls. The Association of American Geographers Annual Meeting, San Francisco, California, United States, April.

Jeffs, T. (1997) Changing Their Ways- Youth Work and Underclass Theory. In R. MacDonald (ed.) Youth, the Underclass and Social Exclusion. London: Routledge, 153-166.

McCahill, M. (1998) Beyond Foucault: towards a contemporary theory of surveillance, in C. Norris, J. Moran and G. Armstrong (eds.) Surveillance, Closed Circuit Television and Social Control. Aldershot: Ashgate, 41-65.

Metropolitan Police (2000) Romford Town Centre Partnership Against Crime. Available at http://www.met.police.uk/havering/romford.htm

Miller, D., Jackson, P., Thrift, N., Holbrook, B. and Rowlands, M. (1998) Shopping, Place and Identity. London: Routledge.

Office of the Deputy Prime Minister (2003) Sustainable Communities: Building for the Future. London: Office of the Deputy Prime Minister.

Philips, S. and Cochrane, R. (1998) Crime and Nuisance in the Shopping Centre: A Case Study in Crime Prevention, Crime Prevention Unit Paper 16. London: Home Office.

Reeve, A. (1998) The panopticanisation of shopping: CCTV and leisure consumption. In C. Norris, J. Moran and G. Armstrong (eds.) Surveillance, Closed Circuit Television and Social Control. Aldershot: Ashgate, 69-87.

Roderick, I. (1998) Consumption Spaces and Meeting Places. Architecture/Research/Criticism, No 5.

Shields, R. (1989) Social Spatialisation and the Built Environment: The West Edmonton Mall. Environment and Planning D: Society and Space, 7(2): 147-164. 
Shields, R. (1992) Spaces for the Subject of Consumption. In R. Shields (ed.) Lifestyle Shopping: The Subject of Consumption. London: Routledge, 99-113.

Smithsimon, G. (1999) The Technologies of Public Space and Alternatives to a Privatised New York. Available at http://www.columbia.edu.

Social Exclusion Unit (2001) National Strategy for Neighbourhood Renewal. London: Cabinet Office.

Whelan, A., Wrigley, N., Warm, D. and Cannings, E. (2002) Life in a 'Food Desert'. Urban Studies, 39(11): 2083-2100.

White, R. (2001) Sanitary Cities: How Designers Banish the young and Poor from the Public Realm. Architecture Australia, 83(3): 52-66.

Williams, C. and Windebank, J. (2002) The 'excluded consumer': a neglected aspect of social exclusion? Policy and Politics, 30(4): 501-513.

Wrigley, N. (2002) 'Food Deserts' in British Cities: Policy Context and Research Priorities. Urban Studies, 39(11): 2029-2040.

Wrigley, N., Guy, C. and Lowe, M. (2002) Urban Regeneration, Social Inclusion and Large Store Development: The Seacroft Development in Context. Urban Studies, 39(11): 2101-2114.

Zukin, S. (1991) Landscapes of Power: from Detroit to Disneyworld. Berkeley: University of California Press. 